of the hospital to do so. This is potentially a source of conflict because any of several people could go to court to apply for the warrant. Each of them could say that they were too busy to go to court, or that they had been doing so more often than the others, and the matter would remain unresolved, to the detriment of the patient whose mental state might be deteriorating while he or she is out of hospital and without treatment.

We therefore recommend that the health and social services providing care for the residents of every locality should agree a local policy regarding the implementation of Section 135, and that such a policy should specifically address the question of who should go to court to apply for the warrant under Section 135(2).

JENNIFER FERREIRA, Manager, Southwood Hospital, Camden and Islington Community Health Services NHS Trust, Southwood Lane, Highgate, London N6 5SP; IKECHUKWU AZUONYE, Consultant Psychiatrist/Senior Lecturer, Adult Mental Health Unit, Lambeth Healthcare NHS Trust, 108 Landor Road, Stockwell, London SW9 9NT

\section{Rapid tranquillisation: the cost of treatment}

Sir: Hyde and colleagues concluded that zuclophenthixol acetate was less costly than haloperidol for rapid tranquillisation in a psychiatric intensive care unit (Psychiatric Bulletin, March 1998, 22, 186-190). The reason for this was entirely based on differences in special nursing costs. However, it is not clear why the haloperidol group required more special nursing. This we are not told and the objective data gives little hint as to why this should have been the case. One prediction might have been that the haloperidol group would have been involved in more violent incidents (because of the shorter half-life of the drug) requiring more frequent rapid tranquillisation. In fact, the mean number of incidents per patient were the same in both groups. The key to the apparent paradox appears to lie in the preference of nursing staff for zuclopenthixol acetate. The most common reason for their choice was a reduction in the number of injections required, which is not congruent with the facts reported in this study. Given that the decision for special nursing is mainly a nursing one, I would proffer an alternative explanation for the results, which is that the nurses were more confident with zuclopenthixol acetate and, therefore, the requirement for special nursing was reduced.

In an open study such as this, it is impossible to resolve these different interpretations. Pharmacotherapy plays one part in the management of violent patients, with staff confidence and skills equally important. The extra cost of zuclopenthixol acetate may be a small price to pay for greater confidence, but it would be a shame if this was at the cost of losing the ability to titrate the treatment to match the situation. Titration is much easier with a shorter acting drug.

I. M. ANDERSON, Senior Lecturer/Honorary Consultant in Psychiatry. School of Psychiatry and Behavioural Sciences, Rawnsley Building. Manchester Royal Infirmary, Oxford Road. Manchester M13 9WL

\section{Video newsletter}

Sir: Some years ago I looked at the possibility of producing a quarterly video newsletter for those interested in psychiatry. Clinical tutors with a very long memory may even recall seeing a pilot programme. In the event I thought the amount of support for the venture at the time seemed marginal, particularly in view of the significant start up costs for the project.

Over the years events have moved on. Continuing education commands greater awareness. Production and distribution costs have fallen significantly. There are also innovative developments in distribution and digital technology. Therefore, now may be an appropriate moment to re-visit the idea.

I had in mind a programme with a number of different items covering current affairs in psychiatry, an illustrated lecture and possibly some advertising such as rotational training scheme and hard to fill consultant appointments. No doubt there are many other ideas that can usefully be explored, such as conference reports. For the venture to be successful it would need to command widespread support and the active contributions from a number of enthusiasts. I would be most interested to hear from anyone who would like to cooperate with such an academic venture.

A Macaulay, Consultant Psychiatrist, Wexham Park Hospital, Wexham, Slough, Berks SL2 4HL 